\title{
Editorial
}

\section{Life and death decisions: a biological role for the p75 neurotrophin receptor}

\author{
Freda D. Miller ${ }^{1}$ and David R. Kaplan ${ }^{1,2}$ \\ ${ }^{1}$ Center for Neuronal Survival and \\ 2 Brain Tumor Research Center, Montreal Neurological Institute, McGill \\ University, 3801 rue University, Montreal, Canada H3A 2B4
}

The cellular mechanisms that regulate neuronal survival either during naturally-occurring cell death or in the traumatized mature nervous system are still not wellunderstood. However, over the past several years, evidence has emerged to support the somewhat surprising conclusion that the neurotrophins, perhaps the best-characterized neuronal survival factors, mediate cellular apoptosis via the p75 neurotrophin receptor. These findings are discussed in three separate reviews in this issue of Cell Death and Differentiation and, although all three agree that p $75^{\mathrm{NTR}}$ can mediate apoptosis, none of them agree on the underlying mechanism. In this editorial, we will discuss some of the differences between these models, and will discuss the biological rationale for having a proapoptotic neurotrophin receptor.

\section{Ligand-dependent or independent?}

As discussed in the review by Bredesen et al, (1998, this issue), a number of papers have demonstrated that simply altering the level of $p 75^{\mathrm{NTR}}$ in cells is sufficient to regulate cellular survival; high levels of p75 ${ }^{\mathrm{NTR}}$ caused apoptosis, and decreasing these levels allowed cells to survive (for example, see Rabizadeh et al, 1993). On the basis of these findings, Bredesen and colleagues suggest that $\mathrm{p} 75^{\mathrm{NTR}}$ mediates apoptosis in a ligand-independent fashion. In apparent contradiction, $\mathrm{p} 75^{\mathrm{NTR}}$ in nontransformed cells such as neurons (Bamji et al, 1998) and oligodendrocytes (Casaccia-Bonnefil et al, 1996) must bind neurotrophins to mediate an apoptotic signal, as discussed in the reviews by Barker (1998, this issue) and Casaccia-Bonnefil et al (1998, this issue).

Are these two groups of findings really contradictory? Perhaps not. The term 'ligand-independent' in these studies refers to the absence of exogenous neurotrophins. However, since $\mathrm{p} 75^{\mathrm{NTR}}$ binds to all of the neurotrophins (Rodriguez-Tebar et al, 1990; 1992), and since virtually all cells make one neurotrophin or another, then it is almost inevitable that autocrine or paracrine neurotrophin:p75 NTR loops occur. In the absence of evidence eliminating this possibility, it is not possible to state that $\mathrm{p} 75^{\mathrm{NTR}}$ signals in a ligand-independent fashion. Instead, the difference between these two sets of findings may well be an exogenous versus endogenous source of neurotrophins. This is not to state that $\mathrm{p} 75^{\mathrm{NTR}}$ never signals death in a ligandindependent fashion; only that it has not yet been conclusively demonstrated. One test of the 'ligandindependent' hypothesis would be to assess whether p $75^{\text {NTR }}$ could still induce apoptosis in the presence of function-blocking neurotrophin antibodies.

\section{Trk-dependent or independent?}

The second major difference between the models presented in these reviews involves the role of the Trk family of tyrosine kinase receptors. Barker (1998, this issue) proposes that $\mathrm{p} 75^{\mathrm{NTR}}$ mediates cellular apoptosis primarily by suppressing Trk-mediated survival signals, while Casaccia-Bonnefil et al (1998, this issue), propose that $\mathrm{p} 75^{\mathrm{NTR}}$ directly activates apoptotic signalling cascades. In fact, evidence supports both of these mechanisms, and suggests that they are not mutually-exclusive. With regard to a Trk-dependent mechanism, it is clear that there are multiple interactions between Trk and $\mathrm{p} 75^{\mathrm{NTR}}$ that affect cell survival, and that cross-talk between them is bi-directional. TrkA can suppress $p 75^{\text {NTR }}$. mediated ceramide fluxes (Dobrowsky et al, 1995) and apoptosis of sympathetic neurons (Bamji et al, 1998), while p75 ${ }^{\text {NTR }}$-activation leads to serine-threonine phosphorylation of TrkA (MacPhee and Barker, 1997), and overrides suboptimal TrkA survival signals (Bamji et al, 1998). The most compelling argument that $p 75^{\mathrm{NTR}}$ mediates apoptosis in a Trk-independent fashion derives from two sets of experiments with primary cells. NGF-mediated activation of p $75^{\text {NTR }}$ causes rapid apoptosis of primary oligodendrocytes, where Trk is not active (Casaccia-Bonnefil et al, 1996), and BDNF-mediated activation of $p 75^{\mathrm{NTR}}$ causes apoptosis of sympathetic neurons maintained in $\mathrm{KCl}$ (Bamji et al, 1998), a survival agent that does not activate Trk. These data therefore indicate that $\mathrm{p} 75^{\mathrm{NTR}}$ elicits cell death by both Trk-dependent and Trk-independent mechanisms, and that the relative importance of the two is likely a function of cellular context.

With respect to direct $\mathrm{p} 75^{\mathrm{NTR}}$-mediated signalling cascades, the proapoptotic signals mediated by this receptor have not yet been defined. While a number of studies demonstrate that $\mathrm{p} 75^{\mathrm{NTR}}$ can activate ceramide fluxes (Dobrowsky et al, 1994), and activation of JNK (Casaccia-Bonnefil et al, 1996; Bamji et al, 1998) and NF$\kappa \mathrm{B}$ (Carter et al., 1996), none of these have been demonstrated to be necessary for $p 75^{\mathrm{NTR}}$-mediated apoptosis. We do know, however, that it is the intracellular domain (ICD) of p75 ${ }^{\text {NTR }}$ that signals apoptosis, since expression of the p75 NTR ICD in developing or injured 
neurons of transgenic mice was sufficient to cause apoptosis of selective populations of neurons (Majdan et al, 1997). Whether or not it is the 'death domain' homology found in the ICD (discussed in detail in all three reviews) that is responsible for these effects is still not known.

\section{Is NGF the only apoptotic $p 75^{\mathrm{NTR}}$ ligand?}

With regard to interactions between Trk and $p 75^{\mathrm{NTR}}$ it is also worth revisiting the question of the neurotrophin ligands that act through $p 75^{\mathrm{NTR}}$ to cause apoptosis. Although the original reports indicated that perhaps NGF was the only apoptotic ligand for $\mathrm{p} 75^{\mathrm{NTR}}$ (Frade et al, 1996; Casaccia-Bonnefil et al, 1996), it is now clear that BDNF can function in a similar fashion (Bamji et al, 1998). The confusion in this regard derives from the fact that neurotrophins differentially activate $\mathrm{p} 75^{\mathrm{NTR}}$ on any given cell. What is responsible for these differences? Since Trk signaling can silence p75 NTR signaling, it is likely that the cellular repertoire of Trk receptors determines whether or not a given neurotrophin activates $\mathrm{p} 75^{\mathrm{NTR}}$ and/or is an apoptotic ligand. For example, in the case of sympathetic neurons, the only non-Trk p $75^{\text {NTR }}$ ligand is BDNF, and only BDNF can mediate apoptosis (Bamji et al, 1998), whereas with oligodendrocytes that express the TrkB/BDNF receptor and TrkC/NT-3 receptor, NGF is the only proapoptotic p75 ${ }^{\mathrm{NTR}}$ ligand (Casaccia-Bonnefil et al, 1996). Thus, all neurotrophins likely can signal survival or apoptosis through Trk or p $75^{\mathrm{NTR}}$, respectively, and the ultimate outcome is therefore a function of the precise neurotrophin receptor repertoire and/or cellular context.

\section{A role for $\mathrm{p} 75^{\mathrm{NTR}}$-mediated apoptosis during naturally-occurring neuronal death}

What is the biological rationale for having two neurotrophin receptors, one of which, TrkA, mediates survival, and one of which, p75 NTR, mediates apoptosis? We have recently demonstrated that sympathetic neuron survival during the period of naturally-occurring cell death is determined by the relative levels of activation of TrkA versus $\mathrm{p} 75^{\mathrm{NTR}}$ with TrkA mediating survival, and $\mathrm{p} 75^{\mathrm{NTR}}$ mediating neuronal apoptosis (Bamji et al, 1998). Specifically, when sympathetic neuron survival was maintained with low quantities of $\mathrm{NGF}$ or $\mathrm{KCl}$, BDNF-mediated activation of $\mathrm{p} 75^{\mathrm{NTR}}$ caused neuronal apoptosis and led to increased phosphorylation of c-jun. A physiological role for these observations was demonstrated by examination of $\mathrm{BDNF}^{-1-}$ (Ernfors et al, 1996) and p75 ${ }^{\mathrm{NTR}-1-}$ mice (Lee et al, 1992). In $\mathrm{BDNF}^{-/-}$mice, sympathetic neuron number was increased, and in p75 ${ }^{\mathrm{NTR}-1-}$ mice, the normal period of sympathetic neuron death was greatly delayed (Bamji et al, 1998). This deficit in apoptosis was intrinsic to sympathetic neurons, since cultured p75 ${ }^{\mathrm{NTR}-1-}$ neurons died much more slowly than their wildtype counterparts in the absence of NGF.

On the basis of these findings, we propose that $p 75^{\mathrm{NTR}}$ provides a molecular mechanism for ensuring rapid and active apoptosis when a neuron is unsuccessful in competing for adequate amounts of appropriate neurotrophin. If a sympathetic neuron reaches the appropriate target and sequesters NGF, TrkA is robustly activated, and any coincidental activation of $\mathrm{p} 75^{\mathrm{NTR}}$ is insufficient to override this survival signal. Conversely, if a neuron is late-arriving and/or reaches an inappropriate target, then TrkA would be only weakly induced as a consequence of the lack of NGF, and $p 75^{\mathrm{NTR}}$ would be robustly activated by neurotrophins such as BDNF. Our data indicate that the net outcome of such a scenario would be the rapid apoptotic elimination of that neuron.

Does such a mechanism generalize to neurons other than sympathetic neurons? The most compelling case that it does, to at least some degree, derives from recent studies on basal forebrain cholinergic neurons; in the p75 ${ }^{\text {NTR }-1-}$ mice, the number of basal forebrain cholinergic neurons is increased (Van der Zee et al, 1996), and the innervation is perturbed (Yeo et al, 1997), phenotypes reminiscent of those observed for $\mathrm{p} 75^{\mathrm{NTR}-/-}$ sympathetic neurons. Moreover, a $\mathrm{p} 75^{\mathrm{NTR}}$-mediated death signal may become important in situations of neuronal stress and/or injury. For example, in the $\mathrm{p} 75^{\mathrm{NTR}}$ ICD-expressing transgenic mice, expression of the ICD had no apparent effect on motor neuron development, but induced expression of the p75 NTR ICD following axonal injury led to the death of injured adult facial motoneurons (Majdan et al, 1997).

The neurotrophins are traditionally thought to regulate neuronal survival positively via the Trk family of tyrosine kinase receptors (reviewed in Snider, 1994). Recent findings reviewed in this issue of Cell Death and Differentiation demonstrate that neurotrophins can act both via Trk to promote neuronal survival, and via $\mathrm{p} 75^{\mathrm{NTR}}$ to promote neuronal apoptosis, and define an unexpected apoptotic role for the neurotrophins during naturallyoccurring neuronal death. Such a mechanism, whereby the precise cohort of neurotrophins to which a neuron is exposed determines life versus death provides a level of sophistication that was previously unsuspected. This additional level of complexity provides a mechanism whereby neurons can recognize not only whether they are exposed to the 'right' neurotrophins, but whether or not they are seeing the 'wrong' neurotrophin. Such functional antagonism, mediated by Trk and $\mathrm{p} 75^{\mathrm{NTR}}$ is essential for appropriate sympathetic neuron target innervation, and may well turn out to play an essential role in the matching of neurons with their targets throughout the nervous system.

\section{References}

Bamji SX, Majdan M, Pozniak CD, Belliveau DJ, Aloyz R, Kohn J, Causin CG and Miller FD (1998) The p75 neurotrophin receptor mediates neuronal apoptosis and is essential for naturally-occurring sympathetic neuron death. J. Cell Biol. 140: $911-923$

Barker PA (1998) p75 NTR: A study in contrasts. Cell Death Differ. 5: 346-356

Bredesen DE, Ye X, Tasinato A, Sperandio S, Assa-Munt N, Rabizadeh S (1998) p75 ${ }^{\text {NTR }}$ and the concept of cellular dependence: Seeing how the other half die. Cell Death Differ. 5: 365-371

Casaccia-Bonnefil P, Carter BD, Dobrowsky RT and Chao MV (1996) Death of oligodendrocytes mediated by the interaction of nerve growth factor with its receptor p75. Nature 383: 716-719

Casaccia-Bonnefil P, Kong H, Chao MV (1998) Neurotrophins: the biological paradox of survival factors eliciting apoptosis. Cell Death Differ. 5: 357-364 
Carter BD, Kaltschmidt C, Kaltschmidt B, Offenhauser N, Bohm-Matthaei R, Baeuerle PAand Barde Y-A (1996) Selective activation of NF- $\kappa$ B by nerve growth factor through the neurotrophin receptor p75. Science 272: 542-545

Dobrowsky RT, Werner MH, Castellino AM, Chao MV and Hannun YA (1994) Activation of the sphingomyelin cycle through the low-affinity neurotrophin receptor. Science 265: 1596-1599

Dobrowsky RT, Jenkins GM and Hannun YA (1995) Neurotrophins induce sphingomyelin hydrolysis: modulation by co-expression of p75 with Trk receptors. J. Biol. Chem. 270: 22135-22142

Ernfors P, Lee KF and Jaenisch R (1994) Mice lacking brain-drived neurotrophic factor develop with sensory deficits. Nature 368: 147-150

Frade JM, Rodriguez-Tebar A and Barde Y-A (1996) Induction of cell death by endogenous nerve growth factor through its p75 receptor. Nature 383: 166-168

Lee KF, Li E, Huber LJ, Landis SC, Sharpe AH, Chao MV and Jaenisch R (1992) Targeted mutation of the gene encoding the low affinity NGF receptor p75 leads to deficits in the peripheral sensory nervous system. Cell 69: 737-749

MacPhee IJ and Barker PA (1997) Brain-derived neurotrophic factor binding to the p75 neurotrophin receptor reduced TrkA signaling while increasing serine phosphorylation in the TrkA intracellular domain. J. Biol. Chem. 272: 2354723551
Majdan M, Lachance C, Gloster A, Aloyz R, Zeindler C, Bamji S, Bhakar A, Belliveau D, Fawcett J, Miller FD and Barker PA (1997) Transgenic mice expressing the intracellular domain of the p75 neurotrophin receptor undergo neuronal apoptosis. J. Neurosci. 17: 6988-6998

Rabizadeh S, Oh J, Zhong LT, Yang J, BitlerCM, Butcher LL and Bredesen DE (1993) Induction of apoptosis by the low-affinity NGF receptor. Science 261: 345-348

Rodriguez-Tebar A, Dechant G and Barde Y-A (1990) Binding of brain-derived neurotrophic factor to the nerve growth factor receptor. Neuron 4: 487-492

Rodriguez-Tebar A, Dechant G, Gotz R and Barde Y-A (1992) Binding of neurotrophin-3 to its neuronal receptors and interactions with nerve growth factor and brain-derived neurotrophic factor. EMBO J. 11: 917-922

Snider WD (1994) Functions of the neurotrophins during nervous system development: what the knockouts are teaching us. Cell 77: 627-638

Van der Zee CEEM, Ross GM, Riopelle R and Hagg T (1996) Survival of cholinergic forebrain neurons in developing p75(NGFR)-deficient mice. Science 274: $1729-1732$

Yeo TT, Chua-Couzens J, Butcher LL, Bredesen DE, Cooper JD, Valletta JS, Mobley WC and Longo FM (1997) Absence of p75NTR causes increased basal forebrain cholinergic neuron size, choline acetyltransferase activity, and target innervation. J Neurosci. 17: 7594-7605 